\title{
What Drives Fitness Apps Usage? An Empirical Evaluation
}

\author{
Duwaraka Yoganathan and Sangaralingam Kajanan \\ School of Computing, National University of Singapore, Singapore \\ \{duwaraka, skajanan\} @comp.nus. edu.sg
}

\begin{abstract}
The increased health problems associated with lack of physical activity is of great concern around the world. Mobile phone based fitness applications appear to be a cost effective promising solution for this problem. The aim of this study is to develop a research model that can broaden understanding of the factors that influence the user acceptance of mobile fitness apps. Drawing from Unified Theory of Acceptance and Use of Technology (UTAUT) and Elaboration Likelihood Model (ELM), we conceptualize the antecedents and moderating factors of fitness app use. We validate our model using field survey. Implications for research and practice are discussed.
\end{abstract}

Keywords: Fitness apps, mobile apps, physical activity.

\section{Introduction}

Increasing sedentary lifestyle has resulted in obesity and overweight. According to World Health Organization, worldwide obesity has more than doubled since 1980 and 3 million deaths from heart disease, diabetes and certain cancers are caused by obesity and overweight. However obesity is preventable.

The current healthcare system does not have sufficient resources to prevent and manage these preventable health risks. Therefore, individual effort is paramount in disease prevention, i.e., managing the risks before they develop into more serious health problems. Regular physical activity can not only help individuals to prevent these health risks, but also would enable them to lead a healthy lifestyle.

Mobile phone based interventions hold promise for healthy behavioral change. As immediacy of consequences to a target behavior is important for behavior modification (Skinner, 1969), using mobile phones for promoting healthy behaviors is more effective. The mobile phones will be in the users' vicinity almost all the time and enable immediate feedback to users' behavior. Smartphones and mobile apps are the latest mobile interventions. Smartphone apps are embedded with sophisticated sensors that could monitor the user's behavior. Therefore mobile apps are a viable cost effective solution for self-health management.

While having recognized the advantages and demands to employ mobile apps in healthcare, healthcare apps have a high dropout rate with $26 \%$ of apps being used only once and $74 \%$ of apps being discontinued by the tenth use (McLean, 2011). The high churn rate with healthcare apps is concerning to the healthcare practitioners and researchers as Smartphone apps are beginning to play an important role in healthcare. 
Studies related on healthcare apps are still in its infancy. A handful of existing studies provides some insides on mobile apps that can be used to blood glucose control, and smoke cessation programs (Valdivieso-López et al 2013). However, research related to adoption of fitness apps is limited.

Realizing importance of smartphone apps in healthcare, the purpose of this study is to deepen our understanding of the factors that influence tendencies to use fitness apps, which in turn will improve physical activity behavior of users. Drawing from Unified Theory of Acceptance and Use of Technology (UTAUT) and Elaboration Likelihood Model (ELM) we conceptualize our model. A filed survey was conducted to validate our conceptual model.

This paper is organized into six sections including this introduction. The next section surveys the salient literature, from which we draw our constructs for user acceptance of mobile fitness apps. The third section presents the research model and develops the research hypotheses characterizing the relationships depicted in the model. The fourth section describes our research methods, while the fifth discusses the results and their implications for research and practice. The last section summarizes the study's contributions.

\section{Theoretical Background}

We review literature on IS acceptance, usage, and persuasion to understand the factors of fitness app acceptance and integrate them into a model.

\subsection{Unified Theory of Acceptance and Use of Technology (UTAUT)}

Venkatesh, et al (2003), developed a unified technology acceptance model by synthesizing the elements of eight different theories. This model conceptualizes that performance expectancy, effort expectancy, social influences, and facilitating conditions as important antecedents for the intention to use and subsequently the IT usage behavior. We have chosen UTAUT as theoretical lens for our study, because it a unified theory that includes concepts from various technology acceptance theories such as theory of reasoned action, technology acceptance model, motivational model, theory of planned behavior, a combined theory of planed behavior/technology acceptance model. Thus UTAUT can better explain the adoption of fitness apps.

In addition to the factors that influence the intention to use fitness app, certain persuasive factors can moderate the influence. We use Elaboration Likelihood Model (ELM) to explain the moderating effect on the factors that influence the intension to use fitness app.

\section{Elaboration Likelihood Model (ELM)}

ELM is a dual process theory about how attitudes are formed and changed. The model has two routes of persuasion namely the central route and peripheral route (Petty and Cacioppo 1986). Central path is used when the individual is motivated and think about the message. When the individual is motivated, cares about the issue then he/she will elaborate on the message and lasting persuasion likely. In contract if the 
person has unfavorable attitude towards the issue, persuasion is unlikely. If the person has neutral attitude about the issue and not motivated to listen to the message, then he/she would look for peripheral cues. Usually expert judgment and message credibility are considered as peripheral cues (O'Keefe, 1990). If the peripheral cue association is accepted then the individual may develop a temporarily attitude change for persuasion. If peripheral cue is not accepted, or not present, then person will not be persuaded with the message.

\section{$4 \quad$ Research Model and Hypothesis}

We have conceptualized that individuals use different paths in adopting fitness apps to do physical activity. When individual choose a central path UTAUT factors (such as performance expectancy of fitness app, effort expectancy of fitness app, social influence to use fitness app and facilitating conditions) strongly predict fitness app adoption. However, when individuals choose peripheral path UTAUT factors become less significant predictors of fitness app adoption (Refer fig1).

\subsection{Intention to Use Fitness App (BI)}

Behavioral intention to use fitness app can be defined as a measure of the strength of one's intention to use a mobile fitness app (Fishbein \& Ajzen, 1975, p. 288). According to technology acceptance literature behavioral intension is an accurate predictor of actual use (Davis, 1989). In this study we use behavioral intention to use fitness app as a proxy to user acceptance of fitness app. Thus, we use Behavioral intention to use fitness app as the DV in our study.

\subsection{Intrinsic Motivation to Physical Activity}

Intrinsic motivation toward physical activity refers the degree to which an individual feel pleasure or satisfaction while engaging in physical activity. Researchers have suggested that regardless of one's initial motive for exercising (such losing weight and attractive appearance), intrinsic motivation is critical for exercise adherence and maintaining physical activity behavior (Brawley and Vallerand 1984). Extrinsic reasons for participation may lead to poor exercise adherence rates, since extrinsically focused individuals may derive less enjoyment from the activity itself. Studies have found that lack of enjoyment to be a primary reason for withdrawing from physical activity programs (Boothby, et al 1981). Therefore to the extent that one exercises for intrinsic reasons, he/she is more likely to feel energized, confident, and satisfied and continue physical activity for a longer duration (Frederick ad Ryan (1993). Thus intrinsic motivation is a key factor for exercise adherence.

\subsection{Credibility of Information in Fitness App}

Credibility of Information in fitness app refers the truthfulness, trustworthiness and reliability of the information in a fitness app. Credibility of information in fitness app is decided by the reputation of the source from which, the information is taken. Evidence based information and information with scientific basis are perceived to be 
highly credible. According to Patrick Wilson's cognitive authority theory (1983), individuals trust the source, based on the cognitive authority of the source i.e. the source should be trustworthy or is of high reputation. For example information from US department of Health \& human services could be highly credible. Due to the indispensability of source credibility in health care, trusting the provider is critical in usage intention (Lanseng and Andreason, 2007; Pavlou, 2003 ).

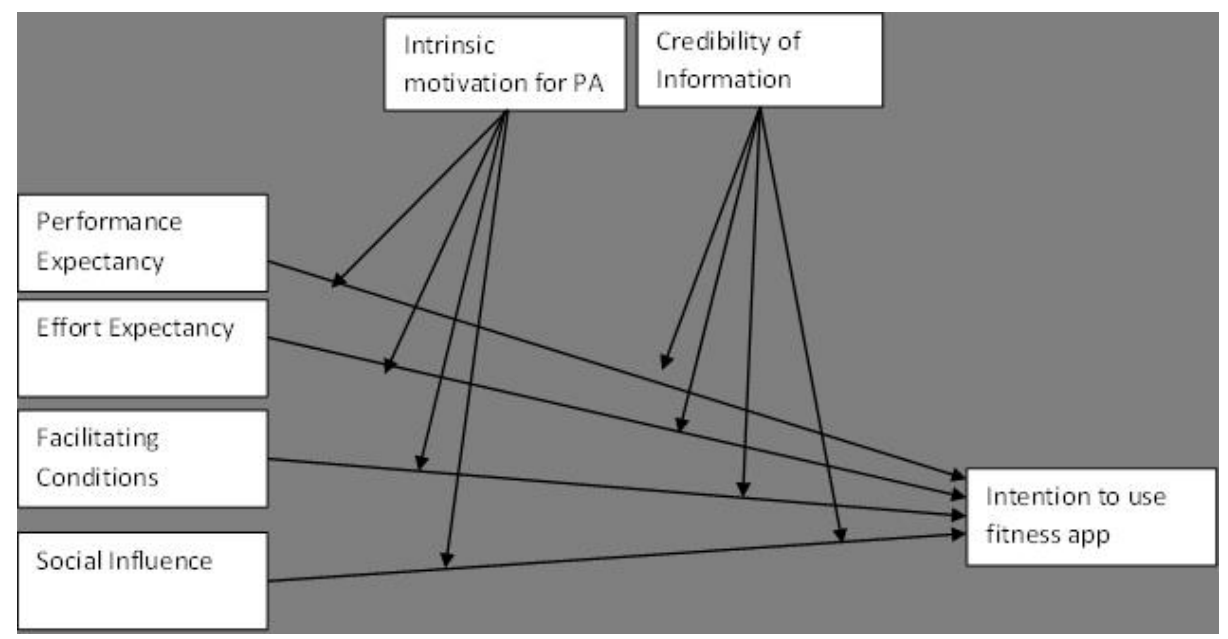

Fig. 1. User Acceptance model for fitness apps

\subsection{Performance Expectancy of Fitness App}

Performance Expectancy of fitness app is defined as the degree to which an individual believes that using the fitness app will help him/her to attain gains in physical activity performance or achieve physical activity goals. A user can speculate that by using a fitness app he/she could be at relative advantage of being more physically active, adhere to scheduled exercise programs, quickly loose weight within a short period /become more attractive and achieve physical activity goals. Thus, an individual believes that using the fitness app he/she would improve his/ her ability to enhance the effectiveness in managing the health and fitness. Several previous studies have indicated that performance expectancy or perceived usefulness of a technology is associated with the acceptance of the technology (Jimison et al, 2008; Boberg et al, 1995; Lai et al, 2008; Wilson and Lankton, 2004; Venkatesh et al, 2003; Davis et al, 1989). Therefore, users will be more likely to adopt the fitness app, or intend to use it if they expect higher exercise performance by using the fitness app. However, from theoretical point of view, it is reasonable to expect that performance expectancy and intention to use fitness app will be moderated by intrinsic motivation to physical activity, and credibility information in fitness app.

Drawing from ELM, when individuals are intrinsically motivated they are likely to choose central path (Petty and Cacioppo 1986) in the adoption of fitness app. Intrinsically motivated individuals will be regularly exercising, due to their fitness enthusiasm 
(Brawley and Vallerand 1984). Therefore they would use the fitness app only if they expect greater performance out of the fitness app. Thus, we can expect a stronger the relationship between performance expectancy and intention to use fitness app among individuals who are intrinsically motivated to exercise.

However, when individuals are not fitness enthusiast and if the app provides credible information, peripheral path will be chosen in adopting fitness app. When peripheral cues such as credibility of the source is demonstrated, the trustworthiness of the app is increased (Lanseng and Andreason, 2007; Pavlou, 2003). If users highly trust the app, then it is less likely they expect greater performance out of the fitness app in order to use it. Thus, we can expect a weaker the relationship between performance expectancy and intention to use when the app provides credible information. Thus we hypothesize:

H1: The influence of performance expectancy on behavioral intention to use fitness app will be moderated by individual's intrinsic motivation for exercise and credibility of information provided by fitness app. Such that the relationship will be stronger when the user is intrinsically motivated to exercise and the relationship will be weaker when the app provides credible information.

\subsection{Effort Expectancy of Fitness App}

Effort expectancy of fitness app is defined as the degree of ease associated with using the fitness app. When user perceive ease or less effort in using the app its highly likely that they accept the fitness app. Using short cuts and user friendly interface designs can enable users to expend less effort from user side in order to carry out the task. Previous studies on technology acceptance indicate that perceived ease of use positively predict acceptance (Kerr et al, 2002; Kleijnen et al, 2004; Lee et al, 2002). Thus individuals are more likely to accept a fitness app if they feel that the app is easy to use.

As intrinsically motivated individuals are regular exercisers (Brawley and Vallerand 1984) they would choose a central path in adopting fitness app (Petty and Cacioppo 1986). In that sense they are likely to use the fitness app only if the app extremely easy to use. Thus, we can expect a stronger the relationship between performance expectancy and intention to use fitness app among individuals who are intrinsically motivated to exercise.

However, when the individuals are not fitness enthusiast and if the app provides credible information, the user will be choosing a peripheral path in using the fitness app. When peripheral cues such as credibility of the source is established, the trustworthiness of the app is demonstrated (Lanseng and Andreason , 2007; Pavlou, 2003). Hence perceived ease of use would less is likely to be significant factor in adopting the fitness. Thus, we can expect a weaker the relationship between performance expectancy and intention to use when the app provides credible information. Thus we hypothesize

H2: The influence of effort expectancy on behavioral intention to use fitness app will be moderated by individual's intrinsic motivation for exercise and credibility of information provided by fitness app. Such that the relationship will be stronger when the user is intrinsically motivated to exercise and the relationship will be weaker when the app provides credible information. 


\subsection{Social Influence}

Social Influence in fitness app is defined as the degree to which an individual perceives that important others believe he/she should use the fitness app. Social support has been speculated to promote general health, wellbeing and healthy lifestyle modifications including smoke cessation (Deelstra, M. C. Peeters, et al. 2003, Dormann, and Zapf, 1999). Social influences act as an environmental stimulus for a person to take positive actions in maintaining good health (Fredrickson, 2000; Sloan and Gruman, 1988). In addition, previous studies have found that the perceived relationship strength of an individual with their colleagues has a positive effect on participation in offline health programs (Cohen and Syme, 1985; Prochaska et al, 1985). Extending the similar logic to the mobile heath apps, when a conducive social environment exist with supportive social ties encouraging exercise and usage of fitness app it reinforces user's positive beliefs about fitness app. Hence an individual is more likely to have a higher intention to use fitness app.

Drawing from ELM, when individuals are intrinsically motivated they are likely to adopt central path for using fitness app (Petty and Cacioppo 1986). Since intrinsically motivated individuals are enthusiastic about exercising they are likely to perform exercises with variety of methods (Brawley and Vallerand 1984). Hence they are more likely to adopt a fitness app only if peers strongly influence using the app. Thus, we can expect a stronger the relationship between social influence and intention to use fitness app among individuals who are intrinsically motivated to exercise.

However, when individuals are not enthusiast about exercise and if when fitness app provides credible information, peripheral path will be chosen in fitness app adoption. If the app demonstrate credibility of the source, it is highly likely the app is trusted by the users (Lanseng and Andreason , 2007; Pavlou, 2003). When the app is trustworthy, influence of others (e.g peers, colleagues, family, friends) is less likely to impact fitness app adoption. Thus, we can expect a weaker the relationship between social influence and intention to use when the app provides credible information. Therefore we hypothesize:

H3: The impact of social influence on behavioral intention to use fitness app will be moderated by individual's intrinsic motivation for exercise and credibility of information provided by fitness app. Such that the relationship will be stronger when the user is intrinsically motivated to exercise and the relationship will be weaker when the app provides credible information.

\subsection{Facilitating Conditions}

Facilitating conditions in fitness app is defined as an individuals' perceptions of internal (i.e. familiarity, knowledge and self-confidence in his/her ability of using apps) and external conditions (i.e, the compatibility of the fitness app platform with the mobile phone: iOs, Android) on using the fitness app. Studies of healthcare literature and studies outside healthcare have shown that facilitating conditions significantly predict acceptance and use of information technology. (Ajzen 1991; Taylor S, Todd , 1995; Venketesh et al, 2003, Moore and Benbasat, 1991, Thompson et al. 1991). Prior studies on technology acceptance by healthcare professionals found that when the mobile heath system (MHS) is well matched with clinical and patient care working practices, then the MHS will be highly accepted(Fitch, 2004; Haron et al, 2004). Using the same logic regular mobile apps users have greater tendency to download, install and use a fitness apps. 
Drawing from ELM, when individuals are intrinsically motivated to exercise they use the central path in adopting a fitness app (Petty and Cacioppo 1986). Exercise enthusiastic would be doing exercise regularly with enthusiasm, therefore if facilitating conditions are also conducive, (for example if the individual is familiar with using mobile apps), they will have a stronger tendency to use fitness apps, in order to try different types of physical activities to satisfy their intrinsic needs (Ryan and Deci 2000). Thus, we can expect a stronger the relationship between facilitating conditions and intention to use fitness app among individuals who are intrinsically motivated to exercise.

In contrast, when the individuals are not fitness enthusiast and if the fitness app provides credible information, the users would choose the peripheral path in adopting the fitness app. This is because when the peripheral cues such as credibility of the source is provided user's trust in the app would be increased (Lanseng and Andreason , 2007; Pavlou, 2003) and it is less likely for the facilitating conditions (such familiarity with apps) to have a significant impact in adopting the fitness app. Thus, we can expect a weaker the relationship between facilitating condition and intention to use. Therefore we hypothesize:

H4: The influence of facilitating condition on behavioral intention to use fitness app will be moderated by individual's intrinsic motivation for exercise and credibility of information provided by fitness app. Such that the relationship will be stronger when the user is intrinsically motivated to exercise and the relationship will be weaker when the app provides credible information.

Table 1. Formal Definitions of Constructs

\begin{tabular}{|l|l|}
\hline Construct & Definition \\
\hline Intention to use fitness app & $\begin{array}{l}\text { The measure of the strength of one's intention to use } \\
\text { fitness app (Adopted from Fishbein \& Ajzen, 1975, p. } \\
\text { 288); }\end{array}$ \\
\hline $\begin{array}{l}\text { Performance Expectan- } \\
\text { cy(PE) }\end{array}$ & $\begin{array}{l}\text { The degree to which an individual believes that using } \\
\text { fitness app will help him/her to attain gains in physical } \\
\text { activity performance. (Venkatesh et al 2003) }\end{array}$ \\
\hline $\begin{array}{l}\text { Intrinsic motivation to } \\
\text { Physical Activity(IM) }\end{array}$ & $\begin{array}{l}\text { The degree to which an individual feel pleasure or } \\
\text { satisfaction while engaging in physical activity. }\end{array}$ \\
\hline Effort Expectancy(EE) & $\begin{array}{l}\text { The degree of ease associated with the use of the fit- } \\
\text { ness app.(Venkatesh et al 2003) }\end{array}$ \\
\hline Social Influence(SI) & $\begin{array}{l}\text { The degree to which an individual perceives that im- } \\
\text { portant others believe he/ she should use the fitness } \\
\text { app (Venketesh et al 2003) }\end{array}$ \\
\hline Facilitating Conditions(FC) & $\begin{array}{l}\text { The perceptions of internal (i.e. familiarity of using } \\
\text { mobile apps, and self-confidence in his or her ability to } \\
\text { of using fitness app) and external constraints (i.e., the } \\
\text { compatibility of the fitness app platform with the mo- } \\
\text { bile phone) on using fitness app (Ajzen, 1991, p. 188). }\end{array}$ \\
\hline $\begin{array}{l}\text { Credibility of Information } \\
\text { in fitness app (CRED) }\end{array}$ & $\begin{array}{l}\text { The truthfulness, trustworthiness and reliability of the } \\
\text { information provided in the fitness app }\end{array}$ \\
\hline
\end{tabular}




\section{$5 \quad$ Research Methodology}

Survey methodology was used to collect data for testing the research hypothesis. Survey methodology was chosen because it enhances generalizability of results.

\subsection{Instrument Development}

Table 1 illustrates the definition of constructs. Constructs were measured using questions adapted from prior studies to enhance validity and new constructs were developed based on the review of Healthcare and Mobile Technologies literature. All items were anchored on a 7-point Likert scale ( $1=$ Strongly Disagree; $7=$ Strongly Agree $)$. Additionally, data was collected for several control variables that may influence our findings. i.e Gender, Age, Education Level, Prior Experience with Smartphones and mobile apps. Face and content validity of all items were assessed. First, items were examined by 3 colleagues with expertise in methodology and subject area to identify problems in framing and wordings of the questions. Second, conceptual validity of the instrument was tested by conducting label sorting with four judges (Moore and Benbasat, 1991). Minor modifications were made based on the sorting results. Two academics were asked to review the survey questionnaire for clarity, content validity, and semantic consistency before a pilot study was conducted.

\subsection{Pilot Study}

Pilot study involved convenient sample of 10 graduate students who were familiar with mobile health apps were given the initial questionnaire. Based on the feedback from pilot study, minor revisions were made to the instrument. Particularly, some participants commented on the difficulty in interpreting the negatively worded item "Source information in the fitness app is not important to me in order to use it". To reduce the confusion the item was rephrased as "Source information in the fitness app is important to me in order to use it". Marsh (1996) indicate that "the potential advantages of including negatively worded items seemed to be offset by associated problems in the present investigation, and these results may generalize to other applications" (p. 817).".

Further, some similarly phrased items were deleted as long as the deletion would not affect the content validity of the scales. This was done to save the time consumed to respond the questionnaire and to reduce the redundancy. The resultant survey instrument was used in the fiend survey.

\subsection{Survey Administration}

The field study was conducted among undergraduate and post graduate students, over a period of 2 weeks in October, 2011. All of the respondents possessed Smartphones. Among the 120 undergraduate and post graduate students recruited for the study, 103 responses were returned (86 percent response rate). Out of the 103 collected responses, 20 responses with incomplete data were eliminated from further analysis. The responses were discarded since the missing data could not be recovered due to the anonymous nature of our survey. The remaining 83 responses were used in the data analysis. 
Most of the respondents were in the age group of 21-30 years (87.95\%) and males $(55.4 \%)$. A majority of respondents were post graduates $(67.47 \%)$ with the rest undergraduates. Most of the respondents had smartphones $(92.67 \%)$ and out of which majority of them used mobile apps $(90 \%)$. Majority of respondents had used Smartphone for a period of 1.5 years.

Nonresponse bias was assessed by verifying that (1) respondents' demographics were similar to that of other undergraduate and graduate students, and (2) early and late respondents were not significantly different. The first set of tests compared gender, age, education, and smartphone usage. The second set of tests compared these characteristics, plus all principle constructs for the two groups. All possible t-test comparisons between the means of the two groups in both sets of tests showed insignificant differences $(\mathrm{p}<0.1$ level).

\subsection{Data Analysis and Results}

Partial Least Squares (PLS)(Chin 1998), a Structured Equation Modeling (SEM), was used for testing the conceptual model and hypothesis. PLS analysis concurrently test the psychometric properties of each scale used to measure the construct in the model and analyze the strength and directions of the relationships among the constructs. Thus, PLS handle both formative and reflective measures that occur jointly in a model. In our study, the constructs Performance Expectancy (PE), Effort Expectancy (EE), intention to use (INT), Social Influence (SI), and Intrinsic Motivation for Physical Activity(IM) were reflective because these constructs were uni-dimensional and exclusion of an item did not alter the meaning of construct. The constructs Credibility of Information in fitness app (CRED) and facilitating conditions (FC) were considered formative because each item jointly determined the meaning of a construct and exclusion of an item could alter its meaning.

PLS is also less stringent about the distribution assumption and sample size to validate the model compared to alternative structural equation modeling techniques. SmartPLS2 bootstrap (BT) methods were used to assess the measurement model and structural model. In addition, the data was standardized according the PLS requirements, before testing.

\subsection{Test of Measurement Model}

Recommended two-stage analytical procedures (Anderson and Gerbing 1988; Hair et al, 1998) were carried out. Confirmatory factor analysis was first conducted to assess measurement mode, then structural relationships were examined. Assessment of measurement model includes evaluation of internal consistency, convergent validity and discriminant validity of the instrument items. Reflective and formative constructs were treated differently during validation because, unlike reflective constructs, different dimensions of formative constructs are not expected to demonstrate internal consistency and correlations. To assess the relevance and level of contribution of each item to the formative constructs, we examined the items weights instead.

For reflective constructs, internal consistency was assessed using Cronbach's alpha reliability coefficients. All reflective constructs in our model had Cronbach's alpha scores that exceeded the criterion of 0.7 (Nunnally 1978). Convergent Validity was 
asses through item reliability, composite reliability and Average Variance Extracted (AVE) for each construct. Convergent validity reflects the extent to which the items of the constructs are similar. All items t-value of loadings were significant. All reliabilities, item composite reliability (CR) were well above the recommended threshold of 0.7 and all AVE were well above the threshold of 0.5(Hair et al, 1998).

Discriminant validity reflects the extent to which the items of each constructs are distinctly different from items of other constructs. This is generally assessed by factor analysis, in which items of each construct load more highly on their intended construct than on other constructs (Thompson et al. 1991; Cook and Campbell 1979). In addition, Discriminant validity can also be assessed by ensuring each item should correlate more highly with other items that measure the same construct than with the items measuring other constructs. For this study, both factor analysis using principal component analysis and verimax rotation and item correlations (i.e squared correlation between constructs compared with AVE of the construct) were carried out.

In addition to validity assessment, we also checked for multicollinearity among variables due to high correlations. VIF and tolerance of all construct variables were within the acceptable thresholds.

\subsection{Test of Structural Model}

With adequate measurement model and acceptable level of multicollinearity PLS Structural model (Chin 1998) was assessed to determine the explanatory power (i.e variance explained) and the significance of the hypothesized paths. The explanatory power of the structural model was determined by the amount of variance in the dependent variable (intension to use fitness app that) is explained by the model. Our model can explain $60.2 \%$ of the variance in the DV. The explanatory power above $10 \%$ is adequate (Falk and Miller, 1992). Each hypothesis corresponds to path in Structural model. Bootstrapping procedure was used to estimate the significance (Tvalue and the corresponding p-value) of the path coefficients. All statistical tests were assessed at 5\% significance. The results of the analysis are summarized below.

Table 2. Results of Hypothesis testing

\begin{tabular}{|l|l|l|l|l|}
\hline Hypothesis & & $\begin{array}{l}\text { Path coeffi- } \\
\text { cient }\end{array}$ & t-value & Results \\
\hline \multirow{2}{*}{ H1 } & IM*PE & 0.262 & 0.812 & Not supported \\
\cline { 2 - 5 } & CR*PE & -0.859 & $3.538 * * *$ & Supported \\
\hline \multirow{2}{*}{ 2 } & IM*EE & 0.801 & $3.328 * * *$ & Supported \\
\cline { 2 - 5 } & CR*EE & -0.243 & 0.826 & Not supported \\
\hline H3 & IM*SI & 0.463 & $1.695 *$ & Supported \\
\hline \multirow{2}{*}{ H4 } & CR*SI & -0.233 & 1.040 & Not supported \\
\cline { 2 - 5 } & IM*FC & 0.251 & 0.940 & Not supported \\
\cline { 2 - 5 } & $\mathrm{CR} * \mathrm{FC}$ & -0.194 & 0.797 & Not supported \\
\hline
\end{tabular}

Based on the results three hypothesis are partially supported. 


\section{Discussion, Implications and Limitations}

Based on our estimation results, hypothesis 1 is partially supported. I.e. the moderating effect of intrinsic motivation on the relationship between performance expectancy and intention to use fitness app is not supported. This result emphasizes the fact that exercise enthusiastic who are intrinsically motivated to exercise, primarily exercise for enjoyment, interest and satisfaction gained in the physical activity itself (Ryan and Deci 2000). Therefore greater performance expectation out of fitness app is not a major concern for using the app. However the hypothesis on the moderating effect of credibility information is supported. This indicates that when credibility information is provided in fitness app, trustworthiness of the app increased (Lanseng and Andreason , 2007) and users are less likely to look for greater performance expectation in order to use the fitness app.

As hypothesized the moderating effect of intrinsic motivation to exercise on the relationship between effort expectancy and intention to use is supported. This finding indicate that since exercise enthusiast are intrinsically motivated and perform exercise for the enjoyment and satisfaction (Ryan and Deci 2000), they are likely to use fitness app if it is extremely easy to use. The hypothesis on the moderating effect of credible information on relationship between effort expectancy and intention to use is not supported. This shows that is even if the app provides credible information, if the app is not easy to use it is less likely that the user adopt the app for exercising. Thus consistent with the previous findings ease of use is an (Kerr et al, 2002; Kleijnen et al, 2004) important factor in fitness app adoption.

Hypothesis 3 is also partially supported. The moderating effect of intrinsic motivation on the relationship between social influence and intention to use is supported but the moderating effect of credible information is not supported. This shows that since intrinsically motivated individuals are enthusiastic about exercising (Brawley and Vallerand 1984) they are likely to adopt fitness app if their peers strongly recommend using the fitness app. The hypothesis on the moderating effect of credible information is not supported. This shows that credibility of the information does not influence users, when important others prefer him/her using the app. This finding is also consistent with previous finding that colleagues' influence can have a significant impact on an individual's adoption (Prochaska et al, 1985).

Finally, the hypothesis 4 is not supported. The moderating effect of intrinsic motivation to exercise and credibility of information in fitness app doesn't impact the relationship between facilitating condition and intention to use fitness app. This indicates that since intrinsically motivated individuals are regular exercisers they use variety of exercise methods (Brawley and Vallerand 1984) therefore they do not consider mere facilitating condition (such as familiarity with mobile apps) as an important antecedent to use fitness app. Similarly, the finding on the moderating effect of credibility information shows that even if fitness app provides credibility information and facilitating conditions (such as familiarity with mobile apps) are conducive individuals are not likely opt to use fitness app for exercising. This indicates that favorable facilitating condition itself is not sufficient for individuals to adopt fitness apps for exercise. However, fitness app features such as keeping track of goals, measuring progress and health can more important for users (Yoganathan and Kajanan 2013). 


\subsection{Limitations and Future Work}

While interpreting the findings of this study, several limitations need to be recognized. First, the application studied was described to the respondents - they did not actually use it. This makes the results less general than if the system actually had been used by the respondents. For instance, it is hard to see how the respondents could have a good understanding of the system's ease of use from a short description. While this limits this study's generality, it does not invalidate the findings. A number of studies of technology acceptance are done in this way and further, the actual adoption process resembles this when users have to buy the goods before they are able to try them. However, future studies, can design a mobile app with stipulated features, let them actually use the application and increase the study's generality.

Secondly, there may be response bias in our measurement. Our respondents are mainly from students sample and are well conversant with new mobile technologies than those who are deprived of such mobile technologies. Future studies may strive to obtain responses from other populations such as working class, senior citizens and professionals.

Third due to the scale of the survey and the process of eliciting unqualified participants, the size of the sample for the final analysis is limited. Although the sample size is acceptable for PLS analysis, a larger and more heterogeneous sample would bring more statistical power and allow more rigorous testing. Thus, caution needs to be exercised in generalizing our results to other setting, since our study targeted student population.

Fourth, our study did not measure actual use. It is well known that the link between Intention to use and actual use is not perfect. Knowing the respondents' intention does not mean that we know what they will do. The actual behavior of fitness app usage can be measured in future studies. However, with considerable support on intention as a significant predictor of actual usage (Taylor and Todd 1995; Venkatesh and Morris 2000; Venkatesh et al, 2003), this issue may be less critical.

Lastly, we investigated one specific (i.e., health and fitness) mobile behavior change application. Investigating one of a kind is a poor background for generalizing to the whole class. Future studies may be designed to study other type of mobile health apps such as smoking cessation, health and nutrition, and chronic disease control apps. Taken together these caveats suggest that the results are interpreted with care. Moreover, quantitative study can also be conducted in future and provide more insight to this study. Further, future studies can also refine the measures and constructs to get a deeper understanding of the study.

\subsection{Theoretical Contributions}

In a preliminary effort to understand the factors that influence smartphone users' tendencies to use fitness apps, this study attempts to synthesize relevant work from IS technology acceptance, Health care IT, mobile technologies and provides a comprehensive view. In addition, this study explores the various the psychological, technical and social perception of an individual that influence a person's decision making in using a mobile technology that is related to health.

Moreover, the results shows that UTAUT model (Venkatesh et al, 2003) and ELM can be combinedly used to predict fitness app adoption. While UTAUT could be used 
to explain the main antecedent of fitness app use, ELM could be used to explain the moderating factors of fitness app use.

In comparison with most previous IS acceptance studies conducted in workplace settings (Venkatesh et al, 2003; Thompson et al, 1991), this study highlights some of the difference in terms of antecedent for individuals in non-work place situations. Particularly the facilitating conditions in work place setting such as organizational and technical infrastructure that exist to support the system use, do not apply in the context of this study. They are replaced by internal factors such as self-confidence/ individual's ability to use fitness app and external constrains such as compatibility of the operating system, previous experience of using mobile apps.

Apart from the theoretical implications with reference to technology acceptance, this study also contributes to the emerging mobile health technologies.

In terms of methodology, the study suggests insights into how survey instruments can be designed to cater to the reduced cognitive capabilities of the respondents. Thus while designing a survey reverse phrased items may be confusing for respondents and should probably be avoided, and length of the survey questionnaire must be kept manageable.

\subsection{Practical Implications}

Lack of physical activity is a huge problem around the globe. Our literature review suggests that this problem in part can be controlled by mobile interventions. Several practical implications from this study may assist m-health app developers in designing tailored motivational applications.

The present study results indicate that individuals who are more intrinsically motivated to do physical activity may expect greater ease of use and strong social influence in order to use fitness app. Thus, fitness app designers should consider these factors when designing fitness apps.

In addition the findings suggest the significance of credibility of information that in fitness apps. When credible information is provided users may not have greater concerns of performance expectancy. This is an important indication for designers of fitness app to provide reliable, evidence based scientifically proven information in the fitness apps. For example it would be useful to incorporate information such as "Recommended amount of physical activity", by "World Health Organization", "UK physical activity guidelines, "U.S. Dept of Health and Human Services" and "British Heart Foundation" guidelines. Incorporating such information into the fitness apps might increase an individual's trust in fitness app and encourage using fitness app.

Future studies will need to shed more light on the target population relative to system design requirements and marketing, as well as document increases in physical activity due to fitness app usage.

\subsection{Conclusions}

The current research represents a first step in understanding the acceptance of fitness apps. For this reason we choose to apply well known theories and models from theories of technology acceptance, and models of persuasion to test their associations with logically related individual characteristics. By providing empirical evidence regarding 
the antecedents and moderating factors of fitness app, we feel that we have contributed to the development of a richer understanding for fitness app acceptance. Further, by following a rigorous process in defining the constructs and rigorous validation process, the model and finding will be a beneficial contribution for theory and practice.

Given the importance of cost effective mobile healthcare technologies we hope that our findings will be useful in designing effective mobile apps that can improve the health and wellbeing of the public at large. From these finding it is important to expand the research mobile health apps. Research in the area of mobile health technologies is likely to provide deeper insights in the process of creating healthy communities in a cost effective way.

\section{References}

1. Agarwal, R., Karahanna, E.: Time flies when you're having fun: Cognitive Absorption and beliefs about information technology usage. MIS Quarterly 24, 665-694 (2000)

2. Ajzen, I.: The Theory of Planned Behavior. Organizational Behavior and Human Decision Processes 50(2), 179-211 (1991)

3. Atkinson, M.A., Kydd, C.: Individual characteristics associated with World Wide Web use: An empirical study of playfulness and motivation. The DATA BASE for Advancement in Information Systems 28, 53-62 (1997)

4. Anderson, J.C., Gerbing, D.W.: Structural Equation Modeling in Practice; A Review and Recommended Two-Step Approach. Psychological Bulletin 103(3), 41-423 (1988)

5. Becker, M.H., Maiman, L.A., Kirscht, J.P., Haefner, D.P., Drachman, R.H.: The health belief model and prediction of dietary compliance: A field experiment. Journal of Health and Social Behaviour 18, 348-366 (1977)

6. Brawley, L.R., Vallerand, R.J.: Enhancing intrinsic motivation for fitness activities: Its systematic increase in fitness environment (Unpublished manuscript, University of Waterloo) (1984)

7. Boberg, E.W., Gustafson, D.H., Hawkins, R.P., et al.: Development, acceptance, and use patterns of a computer-based education and social support system for people living with AIDS HIV infection. Comput Human Behav. 11, 289-311 (1995)

8. Boothby, J., Tungatt, M.F., Townsend, A.R.: Ceasing participation in sports activity: Reported reasons and their implications. Journal of Leisure Research 12, 1-14 (1981)

9. Chen, C., Czerwinski, M., Macredie, R.: Individual differences in virtual environments introduction and overview. Journal of the American Society for Information Science 51(6) (2000)

10. Chin, W.W.: The Partial Least Squares Approach to Structural Equation Modeling. In: Marcoulides, G.A. (ed.) Modern Methods for Business Research, pp. 295-336. Lawrence Eribaum Associates, Mahwah (1998)

11. Chau, P.Y.K., Hu, P.J.-H.: Investigating healthcare professionals' decision to accept telemedicine technology: An empirical test of competing theories. Information and Management 39, 297-311 (2002)

12. Cohen, S., Syme, S.L.: Social support and health. Academic Press, San Diego (1985)

13. Csikszentmihalyi, M., Rathunde, K.: The measurement of flow in everyday life: Toward a theory of emergent motivation. In: Jacobs, J. (ed.) Nebraska Symposium on Motivation, 8th edn., pp. 57-97. University of Nebraska Press, Lincoln (1992) 
14. Davis, F.D.: Perceived Usefulness, Perceived Ease of Use, and User Acceptance of Information Technology. MIS Quarterly 13, 319-340 (1989)

15. Davis, F.D., Bagozzi, R.P., Warshaw, P.P.: Extrinsic and intrinsic motivation to use computers in the workplace. Journal of Applied Social Psychology 22, 1111-1132 (1992)

16. Davis, F.D., Bagozzi, R.P., Warshaw, P.R.: User acceptance of computer technology: A comparison of two theoretical models. Management Science 35, 982-1003 (1989)

17. Deci, E.L., Ryan, R. M.: Intrinsic Motivation and Self Determination in Human Behavior. Plenum Press, New York (1985)

18. Deelstra, J.T., Peeters, M.C., et al.: Receiving Instrumental Support at Work: When Help Is Not Welcome. Journal of Applied Psychology 88(2), 324-331 (2003)

19. Dickinger, A., Arami, M., Meyer, D.: The role of perceived enjoyment and social norm in the adoption of technology with network externalities. European Journal of Information Systems 17, 4-11 (2008)

20. Dormann, C., Zapf, D.: Social Support, Social Stressors at Work, and Depressive Symptoms: Testing for Main and Moderating Effects with Structural Equations in a Three-Wave Longitudinal Study. Journal of Applied Psychology 84(6), 874-884 (1999)

21. Lanseng, E.J., Andreassen, T.W.: Electronic healthcare: A study of people's readiness and attitude toward performing self-diagnosis. International Journal of Service Industry Management 18(4), 394-417 (2007)

22. Falk, R.F., Miller, N.B.: A primer for soft modeling. The University of Akron Press, Akron (1992)

23. Fredrickson, B.L.: Cultivating positive emotions to optimize health and well-being. Prevention and Treatment 3(1), 1 (2000)

24. Frederick, C.M., Ryan, R.M.: Differences in motivation for sport and exercise and their relationships with participation and mental health. Journal of Sport Behavior 16, 125-145 (1993)

25. Fitch, C.J.: Information systems in healthcare: Mind the gap. In: Proceeding of the 37th Hawaii International Conference on System Sciences (2004)

26. Foa, E., Rothbaum, B., Furr, J.: Augmenting exposure therapy with other CBT procedures. Psychiatric Annals 33(1), 47-56 (2011)

27. Grise, M., Gallupe, B.: Information overload: Addressing the productivity paradox in faceto-face electronic meeting. Journal of Management Information Systems 16(3), 157-185 (1999-2000)

28. Grime, P.R.: Computerized cognitive behavioural therapy at work: A randomized controlled trial in employees with recent stress-related absenteeism. Occup. Med. 54, 353-359 (2004)

29. Gould, S.J.: Consumer attitudes toward health and health care: A differential perspective. The Journal of Consumer Affairs 22(1), 96-118 (1988)

30. Heijden, H.: User acceptance of hedonic information systems. MIS Quarterly 28, 695-704 (2004)

31. Hu, P., Chau, P., Tam, K.: Examining the technology acceptance model using physician acceptance of telemedicine technology. Journal of Management Information Systems 16(2), 91-112 (1999)

32. Jansson, M., Linton, S.J.: Cognitive-behavioral group therapy as an early intervention for insomnia: A randomized controlled trial. J. Occup. Rehabil. 15, 177-190 (2005) 
33. Jayasuriya, R.: Determinants of microcomputer technology use: Implications for education and training of health staff. International Journal of Medical Informatics 50, 187-194 (1998)

34. Kerr, J.H., Fujiyama, H., Campano, J.: Emotion and Stress in Serious and Hedonistic Leisure Sport Activities. Journal of Leisure Research 34, 272-289 (2002)

35. Kraft, F.B., Goodell, P.W.: Identifying the health conscious consumer. Journal of Health Care Marketing 13(3), 18-25 (1993)

36. Kleijnen, M., Wetzels, M., de Ruyter, K.: Consumer acceptance of wireless finance. Journal of Financial Services Marketing 8, 206-217 (2004)

37. Koestner, R., McClelland, D.C.: Perspectives on competence motivation. In: Pervin, L.A. (ed.) Handbook of Personality: Theory and Research, pp. 527-548. Guilford Press, New York (1990)

38. Koh. C.: Ezyhealth \& Beauty (2011)

39. Lai, T.Y., Larson, E.L., Rockoff, M.L.: User acceptance of HIV TIDES-Tailored interventions for management of depressive symptoms in persons living with HIV/ AIDS. J. Am. Med. Inform. Assoc. 15, 217-226 (2008)

40. Lamminmäki, E., Pärkkä, J., Hermersdorf, M., Kaasinen, J., Samposalo, K., Vainio, J., Kolari, J., Kulju, M., Lappalainen, R., Korhonen, I.: Wellness Diary for Mobile Phones. In: EMBEC (2005)

41. Lee, Y., Kim, J., Lee, I., Kim, H.: A crosscultural study on the value structure of mobile internet usage: Comparison between Korea and Japan. Journal of Electronic Commerce Research 3, 227-239 (2002)

42. Lee, G., Tsai, C., Griswold, W.G., Raab, F., Patrick, K.: PmEB: A Mobile Phone Application for Monitoring Caloric Balance. CHI, Work-in-Progress, 1013-1018 (2006)

43. McLean, Motivating Patients to Use Smartphone Health Apps, Consumer Health Information Corporation (April 25, 2011)

44. Marsh, H.S.: Positive and Negative Global Self-Esteem: A Substantively Meaningful Distinction or Artifactors? Journal of Personality and Social Psychology 70(4), 810-819 (1996)

45. Moore, G., Benbasat, I.: Development of an Instrument to Measure the Perceptions of Adopting an Information Technology Innovation. Information Systems Research 2(3), 192-222 (1991)

46. Newsom, J.T., McFarland, B.H., Kaplan, M.S., Huguet, N., Zani, B.: The health consciousness myth: Implications of the near independence of major health behaviours in the North American population. Social Science \& Medicine 60, 433-437 (2005)

47. Nunnally, J.C.: Psychometric Theory. Mcgraw-Hill Book Company, New York (1978)

48. Pavlou, P.A.: Consumer Acceptance of Electronic Commerce: Integrating Trust and Risk with the Technology Acceptance Model. International Journal of Electronic Commerce 7(3), 69-103 (2003)

49. Plank, R.E., Gould, S.J.: Health consciousness, scientific orientation and wellness; An examination of the determinants of wellness attitudes and behaviors. Health Marketing Quarterly 7(3-4), 65-83 (1990)

50. Pelletier, L.G., Fortier, M.S., Vallerand, R.J., Tuston, K.M., Blais, M.R.: Toward a new measure of intrinsic motivation, extrinsic motivation and amotivation in sports: The Sport Motivation Scale (SMS). Journal of Sports \&- Exercise Psychology 17, 35-53 (1995)

51. Prochaska, T.R., Leventhal, E.A., et al.: Health practices and illness cognition in young, middle aged and elderly adults. Journal of Gerontology 40(5), 569-578 (1985) 
52. Reeve, J., Deci, E.L.: Elements of the competitive situation that affect intrinsic motivation. Personality and Social Psychology Bulletin 22(14), 33 (1996)

53. Scheier, M., Carver, C.S.: Effects of optimism on psychological and physical well-being: Theoretical overview and empirical update. Cognitive Therapy and Research 16(2), 201-228 (1992)

54. Sheppard, B.H., Hartwick, J., Warshaw, P.R.: The theory of reasoned action: A metaanalysis of past research with recommendations for modifications and future research. $\mathrm{J}$ Consumer Res. 15, 325-343 (1988)

55. Skinner, B.F.: Contingencies of reinforcement: A theoretical analysis. Prentice-Hall, Englewood Cliffs (1969)

56. Sloan, R.P., Gruman, J.C.: Participation in Workplace Health Promotion Programs - The Contribution of Health and Organizational-Factors. Health Education Quarterly 15(3), 269-288 (1988)

57. Taylor, S., Todd, P.: Understanding information technology usage: A test of competing models. Information Systems Research 6, 144-176 (1995)

58. Thompson, R.L., Higgins, C.A., Howell, J.M.: Personal Computing: Toward a Conceptual Model of Utilization. MIS Quarterly 15(1), 124-143 (1991)

59. Venkatesh, V., Morris, M.G., Davis, G.B.: User acceptance of information technology: Toward a unified view. MIS Quarterly 27, 425-478 (2003)

60. Venkatesh, V., Morris, M.G., Ackerman, P.L.: A longitudinal field investigation of gender differences in individual technology adoption decision-making processes. Organizational Behavior and Human Decision Processes 83(1), 33-60 (2000)

61. Valdivieso-López, E., et al.: Efficacy of a mobile application for smoking cessation in young people: Study protocol for a clustered, randomized trial. BMC Public Health 13(1), 1-6 (2013)

62. Yoganathan, D., Kajanan, S.: Persuasive Technology for Smartphone Fitness Apps (2013)

\section{Appendix A}

Table 3. Results of Confirmatory Factor Analysis

\begin{tabular}{|l|l|l|l|}
\hline Construct & Cronbch's alpha & AVE & CR \\
\hline INT & 0.907 & 0.7973 & 0.9401 \\
\hline PE & 0.869 & 0.7137 & 0.9087 \\
\hline SI & 0.943 & 0.7712 & 0.9818 \\
\hline EE & 0.956 & 0.7905 & 0.9378 \\
\hline IM & & & 0.9721 \\
\hline
\end{tabular}


Table 4. Item Weights for Formative Constructs

\begin{tabular}{|l|l|}
\hline Construct and Items & Item Weights \\
\hline Credibility & 0.2540 \\
\hline CRED1 & $0.5607 \quad *$ \\
\hline CRED2 & $0.6248 \quad * *$ \\
\hline CRED3 & $0.9587 \quad * * *$ \\
\hline CRED4 & $0.7074 \quad * *$ \\
\hline Facilitating Condition & $0.7120^{* * *}$ \\
\hline FC1 & $0.7982 \quad * * *$ \\
\hline FC2 & $0.8834 \quad * * *$ \\
\hline FC3 & FC4 \\
\hline$* \mathrm{p}<0.05 ; * * \mathrm{p}<0.01$ level; $* * * \mathrm{p}<0.001$ level \\
\hline
\end{tabular}

Table 5. AVE Against Square Correlations among Formative Contructs

\begin{tabular}{|l|l|l|l|l|l|}
\hline Constructs & INT & PE & SI & EE & IM \\
\hline INT & $\mathbf{0 . 7 9 7 3}$ & & & & \\
\hline PE & 0.169778 & $\mathbf{0 . 7 1 3 7}$ & & & \\
\hline SI & 0.193226 & 0.029653 & $\mathbf{0 . 7 7 1 2}$ & & \\
\hline EE & 0.177918 & 0.275099 & 0.159509 & $\mathbf{0 . 7 9 0 5}$ & \\
\hline IM & 0.304056 & 0.169778 & 0.029653 & 0.407450 & $\mathbf{0 . 8 9 7 1}$ \\
\hline
\end{tabular}

